\title{
Erratum
}

\section{Burnout and depression among Canadian emergency physicians - ERRATUM}

\section{Kerstin de Wit}

doi: 10.1017/cem.2020.446

De Wit 2020 cites the wrong article in reference 2.

The correct reference details are as follows:

Lim, R., Aarsen, K., Gray, S., Rang, L., Fitzpatrick, J., \& Fischer, L. (2020). Emergency medicine physician burnout and wellness in Canada before COVID19: A national survey. CFEM 2020;22(5):603-607.

\section{REFERENCE}

de Wit K. Burnout and depression among Canadian emergency physicians. CFEM 2020:22(6): 559-560. 